\title{
Update on Menopausal Hormone Therapy for Fracture Prevention
}

\author{
Jan J. Stepan ${ }^{1} \cdot$ Hana Hruskova ${ }^{2,3,4}$ • Miloslav Kverka ${ }^{5,6}$ \\ Published online: 18November 2019 \\ (C) The Author(s) 2019
}

\begin{abstract}
Purpose of Review The goal of the review is to assess the appropriateness of menopausal hormone therapy (MHT) for the primary prevention of bone loss in women at elevated risk in the early years after menopause.

Recent Findings Estrogen alone or combined with progestin to protect the uterus from cancer significantly reduces the risk of osteoporosis-related fractures. MHT increases type 1 collagen production and osteoblast survival and maintains the equilibrium between bone resorption and bone formation by modulating osteoblast/osteocyte and T cell regulation of osteoclasts. Estrogens have positive effects on muscle and cartilage. Estrogen, but not antiresorptive therapies, can attenuate the inflammatory bonemicroenvironment associated with estrogen deficiency. However, already on second year of administration, MHT is associated with excess breast cancer risk, increasing steadily with duration of use.

Summary MHT should be considered in women with premature estrogen deficiency and increased risk of bone loss and osteoporotic fractures. However, MHT use for the prevention of bone loss is hindered by increase in breast cancer risk even in women younger than 60 years old or who are within 10 years of menopause onset.
\end{abstract}

Keywords Bone cells $\cdot$ Estrogens $\cdot$ Fracture $\cdot$ Postmenopausal osteoporosis $\cdot$ Prevention

\section{Introduction}

Osteoporosis is a common disease characterized by low bone mass, microarchitectural disruption, increased skeletal fragility, decreased bone strength associated with increased fracture risk, and mortality associated with fractures [1]. Due to

This article is part of the Topical Collection on Therapeutics and Medical Management

\section{Jan J. Stepan}

stepan@revma.cz

1 Institute of Rheumatology, Prague, Czech Republic

2 Department of Obstetrics and Gynecology, First Faculty of Medicine, Prague, Czech Republic

3 Charles University, Prague, Czech Republic

4 General University Hospital in Prague, Prague, Czech Republic

5 Institute of Microbiology of the Czech Academy of Sciences, v.v.i., Prague, Czech Republic

6 Institute of Experimental Medicine of the Czech Academy of Sciences, v.v.i., Prague, Czech Republic changes in population demography, the annual number of fragility fractures will rise from 3.5 million in 2010 to 4.5 million in 2025 in the EU [2]. Therapies that are effective in osteoporotic women at high risk of fracture are available. However, to significantly impact total fracture numbers, effective options are needed to prevent early accelerated bone loss in women in the first years after menopause and to delay the necessity of antiresorptive therapies in postmenopausal women as they age. Estrogen deficiency is the major cause of the early postmenopausal increase in bone resorption, bone loss and osteoporosis [3]. Randomized clinical studies have demonstrated that estrogen alone, or combined with progestin to protect the uterus from cancer, reduces the risk of osteoporosisrelated fractures. There are currently no clinical guidelines for the management of bone loss in early postmenopausal women. The magnitude of bone remodeling and early bone loss depend on several important genetic factors and bone health characteristics of the women, such as recurrent cycle/ ovulatory disturbances; overall nutrition; body mass index; protein, calcium, and vitamin D intakes; physical activity; adequacy of sleep; the psychosocial environment; and cognitive dietary restraint, modulate the bone tissue sensitivity to estrogen deficiency or other factors. 


\section{Antifracture Efficacy of Menopausal Hormone Therapy}

According to a meta-analysis of several randomized clinical studies published between 1973 and 2000, as a result of MHT, there was a significant $33 \%$ reduction in vertebral fracture [4] and a significant $27 \%$ reduction in nonvertebral fractures [5]. The pooled relative risk (RR) of nonvertebral fractures, hip and wrist fractures was significantly reduced in women younger than 60 years [5]. Subsequent double-blind, randomized, placebo-controlled studies have confirmed a significant increase in bone mineral density (BMD) in women on MHT compared with individuals in the placebo group [6-12].

A prospective postmenopausal estrogen/progestin intervention (PEPI) study evaluated the effects of MHT on BMD in 875 healthy postmenopausal women (age 45 to 64 years). After 3 years, women assigned to conjugated equine estrogens (CEE), $0.625 \mathrm{mg} /$ day plus a progestin; or CEE alone gained significantly more BMD in the lumbar spine and proximal femur than those who received placebo [7].

The results of the National Osteoporosis Risk Assessment (NORA) indicated that current but not past hormone use at baseline was associated with a significantly lower risk of osteoporotic fracture in 1 year compared with nonusers, independent of age, ethnicity, body mass index, lifestyle, years postmenopausal, and site of BMD measurement [8].

The Women's Health Initiative (WHI), a randomized, double-blind, placebo-controlled prevention trial, evaluated postmenopausal women not selected for low BMD (mean age $63.3 \pm 7.1$ years). Women with an intact uterus received $0.625 \mathrm{mg}$ /day CEE plus $2.5 \mathrm{mg}$ /day medroxyprogesterone acetate (MPA) $(n=8506)$ or placebo $(n=8102)$. Women with prior hysterectomy received CEE alone $(n=5310)$ or placebo $(n=5429)$. The CEE + MPA trial was terminated early after a median of 5.6 years owing to findings of an increase in breast cancer risk and the unfavorable risk-benefit ratio of this therapy [9]. The CEE-alone trial was terminated after a median of 7.2 years owing to an increase in stroke risk that was not offset by lower coronary heart disease risk [10]. The median cumulative follow-up was 13.2 years for the CEE + MPA trial and 13.0 years for the CEE-alone trial. During the intervention phase, compared with placebo, significant reductions were observed in vertebral fracture in the CEE + MPA trial (HR 0.68; 0.48-0.96), and in the CEE-alone trial (HR 0.64; 0.44 $0.93)$. Significant reductions were observed in all fractures in both trials (the CEE + MPA trial, HR 0.76, 0.69-0.83; the CEE-alone trial, HR 0.72; 0.64-0.80). In the CEE-alone trial, a significant hip fracture benefit in the CEE-alone group versus the placebo group persisted after an average 6.8 years of follow-up (HR 0.61; 0.41-0.91) [10], and after 13.2 years (HR $0.81 ; 0.68-0.97)[13,14]$. Consistent with the WHI, women in the NORA who were currently on MHT had a $40 \%$ lower incidence of hip fractures compared with those who had never used MHT (adjusted OR, 0.60; 0.44-0.82) [11].

The Million Women Study was conducted primarily to examine the health effects of MHT in postmenopausal women aged 50-69 years [12]. This prospective observational questionnaire study demonstrated that compared with never users, current users of MHT at baseline had a significantly reduced incidence of fracture (RR $0.62 ; 0.58-0.66$ ) [15]. The relative risk of fracture decreased significantly with increasing durations of use. Among current users at baseline, the significant reduction in the relative risk of fracture did not vary significantly according to the personal characteristics of the study participants or whether CEE-only, CEE-progestin, or other types of hormones were used. Past users of hormone therapy at baseline experienced no significant protection against fractures.

According to a meta-analysis [16•] of 28 studies with 33,426 participants and 2516 fractures cases, MHT was associated with a significant reduction in the overall relative risk of total fractures (RR 0.74; 0.69-0.80), hip fractures (RR 0.72; 95\% CI 0.53-0.98), and vertebral fractures (RR 0.63; 0.44 $0.91)$. Women younger than 60 years of age had a lower risk of total fractures (RR $0.55 ; 0.44-0.68$ ) than women $>60$ years of age (RR $0.77 ; 0.71-0.84)$. Estradiol as well as CEE led to a decrease in the risk of total fractures (RR $0.55 ; 0.44-0.70$, and RR $0.77 ; 0.71-0.83$, respectively) [16•]. Interestingly, a significantly greater BMD gain was observed in women who received CEE plus MPA compared with those who received estrogen alone [17]. However, there are no head-to-head fracture prevention trials of estrogen alone vs. estrogen plus MPA/ progesterone.

Alternative dosages and routes of MHT have been shown to be efficacious even at low doses. Oral micronized $17 \beta$ estradiol at a dose of $0.25 \mathrm{mg} /$ day for 3 years in postmenopausal women resulted in significant increases in hip, spine, and total BMD compared with the placebo. This treatment reduced biochemical markers of bone turnover to a degree comparable with an estrogen dose of $1.0 \mathrm{mg} / \mathrm{day}$. The side effect profile of the drug was similar to that of the placebo [18]. The addition of progestogen to estrogen did not interfere with this benefit.

The effect of low-dose estrogen therapy via the transdermal route on bone preservation has been well documented [19-22]. A double-blind, placebo-controlled study was performed in 355 nonosteoporotic postmenopausal women who had hysterectomies with or without oophorectomy. At 2 years, compared with the baseline values, lumbar spine BMD declined by $0.59 \%$ in the placebo group, but it increased by $1.65 \%, 4.08 \%$, and $4.82 \%$ in the estradiol $0.025,0.05$, and $0.075 \mathrm{mg} /$ day groups, respectively [23]. Administration of $0.050 \mathrm{mg} /$ day or $0.025 \mathrm{mg} /$ day transdermal estradiol resulted in a reduction in bone turnover markers to a similar degree [19]. Transdermal administration of $0.014 \mathrm{mg} /$ day estradiol 
was associated with a significant increase in lumbar spine BMD and in total hip BMD compared with the placebo group [20]. A 2-year transdermal administration of estradiol and levonorgestrel resulted in significant increases in the lumbar spine, hip, and total body BMD, in the hormone groups compared with the placebo group [21]. All bone markers were significantly reduced in the hormone groups compared with the placebo group [21]. According to a meta-analysis of nine clinical trials, lumbar spine BMD increased significantly by $3.4 \%$ and $3.7 \%$ after one and 2 years of transdermal estrogen therapy, respectively, compared with the baseline values [22].

Effects of intranasal estradiol (pulsed estrogen therapy) was demonstrated in 386 women, less than 5 years past menopause, randomized to intranasal placebo or estradiol at a dose of $150 \mu \mathrm{g}$ or $300 \mu \mathrm{g}$ daily for 2 years. Women with an intact uterus, treated with estradiol, received $200 \mathrm{mg}$ micronized progesterone per day for 14 days of each 28-day cycle. Compared with placebo, BMD increased significantly by $5.2 \%$ and $6.7 \%$ at the spine and $3.2 \%$ and $4.7 \%$ at the hip as a result of treatment with $150 \mu \mathrm{g}$ and $300 \mu \mathrm{g}$ estradiol, respectively [24]. Serum markers of bone remodeling decreased to premenopausal levels in the treated groups. At least one adverse event (rhinitis, sneezing, and application site reaction) was reported in $94 \%$ of treated women [24].

The effects of discontinuation of estrogen use on the rate of bone loss was demonstrated in observational studies [25], in clinical trials [26, 27], and in a prospective study among past hormone users compared with current users [8]. Postintervention, the fracture risk reductions were attenuated in both WHI trials, but a significant fracture benefit persisted after 13 years for CEE + MPA (HR 0.81;0.68-0.97). In the NORA study, women who stopped using MHT more than 5 years earlier had a similar hip fracture risk as that of never users [11]. In a follow-up of the prospective epidemiological study focusing on risk factors for osteoporosis and cardiovascular disease (the PERF study), 263 healthy postmenopausal women who received either MHT or placebo for 2-3 years with no further bone-sparing treatment until follow-up were reexamined 5, 11, or 15 years after stopping MHT [28•]. The risk of all osteoporotic fractures (OR $0.48 ; 0.26-0.88$ ) and vertebral fractures (OR $0.47,0.24-0.93$ ) was significantly reduced compared with the placebo-treated women [28•].

\section{Bone Effects of Estrogen Deficiency}

After menopause, bone homeostasis is dysregulated by hormonal deficiency, leading to enhanced bone resorption and, consequently, increased bone formation. However, the rate of formation is not able to keep up with the rate of resorption, resulting in net bone loss [29,30]. Estrogen deficiency plays a specific role in the subclinical inflammatory bonemicroenvironment state that is accompanied by an increase in oxidative stress and the generation of advanced glycation end products [31, 32•]. Estrogen deficiency in early postmenopausal women is characterized by progressive osteoclastic hyperactivity associated with an increase in serum concentrations of proinflammatory cytokines (TNF- $\alpha$, IL-1, IL- 6 , and IL-17) and CRP [33-35]; upregulation of RANKL, M-CSF, and M-CSF receptor; and decreased expression of osteoprotegerin [36]. IL-17 levels are significantly elevated in postmenopausal osteopenic or osteoporotic women compared with those in premenopausal women and are positively correlated with the sRANK ligand or the ratio of the sRANK ligand to OPG [37]. The RANK/RANKL/OPG axis is also actively regulated by $B$ cells [38]. The surface concentration of RANKL of the marrow cells, characterized as osteoblast lineage, T cells, or B cells, was increased in estrogen-deficient postmenopausal women compared with premenopausal women. These increases were reversed by estrogen treatment [36]. The relative decrease in bone formation after menopause may be explained by increased sclerostin levels, differentiation of osteoblast progenitors toward the adipocyte lineage, and osteoblast apoptosis induced by products of oxidative stress, including reactive oxygen species $[39,40]$.

Experimentally, the mechanism by which hormonal changes are associated with increased numbers of T cells or macrophage activation was suggested to be a permissive connection between estrogen deficiency, the gut microbiota, inflammation, and TNF- $\alpha$ production [41]. The gut microbiota is a potent modulator of the immune system and numerous other physiological processes, both in the gut and throughout the whole organism. Disruption of gut microbiota is a hallmark of many inflammatory, neurological, neoplastic and metabolic diseases. The gut microbiota achieves this extraordinarily broad scope of effects partly directly, by producing bioactive metabolites, and partly indirectly, by shaping the cellular and humoral response of the host's cells, mainly in the gut epithelial and immune cells [42]. The overall outcome is a result of multiple mechanisms, including preosteoclast proliferation, differentiation and apoptosis, being triggered or blocked by one or several of these cytokines [43]. Maintaining the gut barrier is one of the major functions of the mucosa and its failure is associated with chronic inflammatory diseases, often with the contribution of adherent or invasive microbes [44]. Damage to the gut barrier may lead to the excessive stimulation of the immune system, thus worsening chronic inflammation and barrier function [45]. Intestinal epithelial cells contain estrogen receptors capable of regulating gene transcription. Experimentally, estrogen deficiency was associated with increased gut permeability, an expansion of Th17-activated T cells, and subsequent upregulation of the osteoclastogenic cytokines TNF-a, RANKL, and IL-17. T-follicular helper cells, along with B cells, participate in the formation of germinal centers and antibody production [46]. Estrogens may augment gap junctions and cell-to-cell contact, as well as promote 
changes in the composition and diversity of the gut microbiota, which is associated with immune regulation $[47,48]$.

\section{Bone Effects of Menopausal Hormone Therapy}

The results of in vitro experiments indicated that estrogens suppress RANKL production in T and B cells [36] and significantly reduce the recruitment and increase apoptosis of osteoclasts $[49,50]$. Estrogen replacement reverses the release of TNF- $\alpha$ and IL- 1 from peripheral blood monocytes in women after natural or surgical menopause [33, 51]. After acute estrogen withdrawal in postmenopausal women, the increase in bone resorption was significantly blocked by the TNF-a blocker and to a lesser extent by the IL-1b blocker. However, the markers of bone formation were not significantly reduced [52]. Estrogens increase osteoblast survival and type 1 collagen production [53]. Accordingly, estrogens exert an anabolic effect on bone in cell and tissue studies and in animal models. Estrogens regulate the production of the inhibitor of Wnt signaling, sclerostin [54]. In mice, the sclerostin-Fc vaccination reduced serum sclerostin concentrations, increased serum levels of bone formation markers, alleviated the ovariectomy-induced increase in serum resorption markers, and improved the estrogen deficiency-mediated deterioration of BMD, morphometric characteristics of trabecular bone, and mechanical strength of the femur and lumbar spine [55]. Treatment of postmenopausal women with estrogen or raloxifene reduces circulating and bone marrow plasma levels of sclerostin as well as bone sclerostin messenger RNA (mRNA) [56]. In a study with higher than conventional doses of estrogen replacement $(75 \mathrm{mg}$ implant estradiol every 6 months) in postmenopausal women (mean age 65.6 years), BMD improved in every patient, with a median increase of $31.4 \%$ at the lumbar spine and $15.1 \%$ at the proximal femur [57]. Bone histomorphometry showed a significant increase in cancellous bone volume and wall thickness, indicating net bone gain. A significant positive correlation was found between serum estradiol and posttherapy cortical collagen and between an increase in lumbar spine BMD and cortical collagen content. An increase in collagen turnover rather than just the accumulation of mature collagen with increasing age was supported by an increase in intermediate crosslinks in both cortical and cancellous bone and in mature crosslinks in cortical bone [57].

Important information regarding the effects of MHT in the preservation of bone mass by reducing the rate of osteoclastic bone resorption and maintaining new bone formation was provided by dynamic bone histomorphometry in a randomized, double-blind, clinical prospective trial that enrolled healthy women aged 45-55 years who were treated for 2 years with either cyclic estradiol/norethisterone acetate or placebo
[58•]. Bone biopsies from untreated women demonstrated an increased osteoclastic erosion rate, erosion surface and erosion depth compared with women in the MHT group. In untreated women, delayed osteoclast apoptosis resulted in a longer osteoclast lifespan and increased resorptive activity and erosion depth. The bones of women taking MHT were characterized by preservation of bone balance at individual basic multicellular units (BMUs) (wall thickness-erosion depth) and no change in erosion depth or osteoclastic erosion depth. A relative osteoblastic insufficiency was present in the placebo group because osteoblastic bone formation was unable to keep up with the increase in bone resorption [58•]. Accordingly, a significant decrease in osteoclast number and osteoclastic resorption rate, but not mineralizing surface or bone formation rate, was observed after 6 months of CEE treatment [59].

Both MHT and antiresorptive therapies such as aminobisphosphonates and denosumab increase BMD, reduce bone turnover and are efficacious in the treatment of postmenopausal osteoporosis [60-62]. A reduction in the number of remodeling sites may decrease the probability of trabecular perforation and failure and thus stabilize the trabecular network [63]. However, estrogen but not antiresorptive therapies [64-67], by enabling maintenance of bone formation, can adjust the physiological rate of bone remodeling, and restore quality of bone organic matrix, that affects bone micromechanical properties independently of mineralization [68-72]. Moreover, estrogen but not antiresorptive therapies [73] attenuate the inflammatory bone-microenvironment and maintain the equilibrium between bone resorption and bone formation by modulating osteoblast/osteocyte and $\mathrm{T}$ cell regulation of osteoclasts.

Of importance are beneficial effects of MHT on connective tissue, namely, muscle and cartilage. In a meta-analysis, postmenopausal women treated with MHT had approximately 5\% greater muscle strength than those not on MHT [74]. According to Collins et al. the loss of muscle strength in females resulting from estrogen deficiency appears to be associated with apoptotic pathways that contribute to the loss of muscle mass, inadequate preservation of skeletal muscle mass and reduced quality of the remaining skeletal muscle [75•]. Estrogen may protect skeletal muscle against apoptosis via its effects on hydrogen peroxide-induced apoptosis and mitochondrial dysfunction [75•]. On the other hand, the crosssectional area of the skeletal muscles around the femur was lower in osteoporotic patients who underwent long-term aminobisphosphonate treatment than that of the BMDmatched control postmenopausal women [76].

A significantly lower intervertebral disc height was demonstrated in postmenopausal osteoporotic women when compared with that in untreated nonosteoporotic women who, in turn, had significantly lower disc height than premenopausal women and women taking MHT [77]. Intervertebral disc space shows a progressive decline that almost entirely occurs 
in the first 5-10 years after menopause [78]. Estrogen was shown to have direct chondroprotective effects and to be able counteract cartilage degradation in an in vivo model of increased cartilage turnover [79].

\section{Safety Aspects of Menopausal Hormone Therapy}

According to clinical studies [13, 80], the individual benefit/ risk balance of MHT is very dependent on the type, doses, and duration of MHT as well as the individual risk profile of each woman. These aspects are considered in the guidelines [80-84••].

In women younger than 60 years in the WHI trial, after 13 years of treatment with CEE alone, relative risks were decreased for breast cancer (RR 0.76; 0.52-11) and all cancers (RR 0.80; 0.64-0.99) [85]. However, in the CEE-alone WHI trial, the risk of $\mathrm{ER}+\mathrm{PR}+$ breast cancers was noted to be significant after 15 years of current CEE use (RR 1.48; 1.05-2.07) [86]. Therapy with CEE plus MPA for a median of 5.6 years or with CEE alone for a median of 7.2 years was not associated with risk of cancer mortality during a cumulative follow-up of 18 years [87••]. However, in the CEE + MPA WHI trial, breast cancer risk steadily increased throughout the intervention, and was significantly increased for the entire intervention phase (HR 1.24; 1.01-1.53) [88]. The risk of breast cancer appears to be increased with the increasing duration of use. According to Santen and Yue, an average of 16 years is required for tumors to undergo the 30 doubling times necessary for the occult tumors to reach the threshold for clinical detection [89•]. Thus, CEE plus a progestogen in the WHI study increased the rate of tumor diagnosis [89॰]. Recent individual participant meta-analysis of the worldwide epidemiological evidence from eligible prospective studies of MHT use in 108,647 postmenopausal women who developed breast cancer at mean age 65 years, has concluded that every MHT type, except vaginal estrogens, was associated with excess breast cancer risks, which increased steadily with duration of use $[90 \bullet \bullet$. Breast cancer risks were greater for estrogenprogestagen than estrogen only preparations. Among current users, these excess risks were definite even during second to fourth year (estrogen-progestagen RR 1.60, 95\% CI 1.521.69; estrogen-only RR $1.17,1.10-1.26)$ and were twice as great during years 5-14 (estrogen/progestagen RR 2.08, 2.022.15; estrogen-only RR $1.33,1.28-1.37$ ). According to this meta-analysis, 5 years of MHT, starting at age 50 years, would increase breast cancer incidence at ages 50-69 years by about one in every 50 users of estrogen plus daily progestagen preparations; one in every 70 users of estrogen plus intermittent progestagen preparations; and one in every 200 users of estrogenonly preparations. The corresponding excesses from 10 years of MHT would be about twice as great.
The risk of breast cancer was found to be influenced by the type of MHT used [91]. A prospective, longitudinal cohort study of BRCA1 and BRCA2 mutation carriers indicated that after 10 years of follow-up, the cumulative incidence of breast cancer among women who used estrogen-alone MHT was $12 \%$ compared with $22 \%$ among women who used estrogen plus progesterone MHT $(p=0.04)$ [92]. A meta-analysis of 14 studies of women using estradiol with or without progestogen showed no association between estradiol only and risk of breast cancer; however, the risk was significantly elevated when estradiol was combined with MPA, norethisterone acetate, or levonorgestrel but not when it was combined with progesterone or dydrogesterone [93]. Compared with a conventional dose of $\mathrm{CEE}$, transdermal estrogen was associated with a nonsignificant lower risk of invasive breast cancer (HR 0.75; 0.47 -1.19) [94•].

Importantly, in women younger than 60 years in the WHI trial, after 13 years of treatment with CEE alone, relative risks were decreased for coronary heart disease (RR $0.65 ; 0.44$ 0.96), myocardial infarction (RR 0.60; 0.39-0.91), and allcause mortality (RR $0.78 ; 0.59-1.03$ ) [85]. Treatment with CEE plus MPA for a median of 5.6 years or with CEE alone for a median of 7.2 years was not associated with risk of allcause or cardiovascular mortality during a cumulative followup of 18 years [87 $\bullet$ ]. According to results of a meta-analysis of 19 trials, women who started MHT less than 10 years after menopause or who were less than 60 years old, had significantly lower all-cause mortality (RR $0.70 ; 0.52-0.95)$ and coronary heart disease (RR 0.52; 0.29-0.96) compared with the placebo population [95]. However, this meta-analysis demonstrated a nonsignificant trend toward risk of stroke (RR 1.37; 0.80-2.34), and significant increase in the risk of venous thromboembolism (VTE) (RR 1.74; 1.11-2.73) [95] A meta-analysis of effects of oral versus transdermal estrogen indicated that among women using estrogen-only preparations, oral but not transdermal preparations increased VTE risk (RR 1.48, 1.39-1.58; RR 0.97, 95\% CI 0.87-1.09, respectively) [96•]. In transdermal estrogen users, there was no change in VTE risk in women using micronized progesterone (RR 0.93, 0.65-1.33), whereas norpregnane derivatives were associated with increased VTE risk (RR 2.42, 1.84-3.18). Among women using opposed oral estrogen, there was a higher VTE risk in women using medroxyprogesterone acetate than in those using other progestins [96•].

Ischemic stroke is affected differentially by the route of estrogen administration [16•] due to the hepatic first-pass effect of estrogens when administered orally. Oral but not transdermal estrogen activates the coagulation cascade and increases fibrinolytic activity and may also induce resistance to activated protein $\mathrm{C}$, which has been associated with an increased VTE risk [97. 98].

Other risks associated with MHT include dementia (in women aged $\geq 60$ years) [99], gallbladder disease [100], and urinary incontinence [101]. 


\section{Conclusion}

MHT prevents bone loss and deterioration of the bone microarchitecture [102] and decreases the incidence of osteoporosis-related fractures even in postmenopausal women not diagnosed with osteoporosis, with an efficacy similar to that of bisphosphonates. However, due to differences in the mode of action, estrogen but not antiresorptive therapies can attenuate the inflammatory bone-microenvironment and maintain the physiological equilibrium between bone resorption and bone formation. Importantly, the use of MHT for 5-10 years from the onset of menopause has potentially valuable effects on the bone for many years after MHT discontinuation $[16 \bullet, 28 \bullet]$. Also, MHT during the early postmenopausal years effectively improveshot flashes and night sweats, and may improve other features involved in the genesis of osteoporotic vertebral fractures, namely, the quality of connective tissue.

The evidence of increased risks of breast cancer does not allow recommending MHT for the prevention of bone loss in the population, even in women younger than 60 years old or who are within 10 years of menopause onset. However, MHT should be considered in women with premature estrogen deficiency and increased risk of bone loss and osteoporotic fractures. Selective estrogen receptor modulators [103-106] appear to be an available option to delay the necessity of antiresorptive therapies in postmenopausal women as they age. Clinical trials are needed to test the efficacy, safety and cost-effectiveness of other antiresorptive options in the prevention of accelerated bone loss in the early years after menopause in women with increased risk of an accelerated bone loss in order to reduce the number of future fractures associated with the changing population demography.

Funding Information The authors are supported by Ministry of Health of the Czech Republic, under award NV18-05-00394.

\section{Compliance with Ethical Standards}

Conflict of Interest The authors declare that they have no conflict of interest.

Jan Stepan reports grants from Ministry of Health of the Czech Republic, during the conduct of the study. Miloslav Kverka reports grants from Ministry of Health of the Czech Republic, during the conduct of the study.

Hana Hruskova declares no conflict of interest.

Human and Animal Rights and Informed Consent This article does not contain any studies with human or animal subjects performed by any of the authors.

Open Access This article is distributed under the terms of the Creative Commons Attribution 4.0 International License (http:// creativecommons.org/licenses/by/4.0/), which permits unrestricted use, distribution, and reproduction in any medium, provided you give appropriate credit to the original author(s) and the source, provide a link to the Creative Commons license, and indicate if changes were made.

\section{References}

Papers of particular interest, published recently, have been highlighted as:

- Of importance

• Of major importance

1. Kanis JA, Cooper C, Rizzoli R, Reginster JY, et al. European guidance for the diagnosis and management of osteoporosis in postmenopausal women. Osteoporos Int. 2019;30(1):3-44.

2. Hernlund E, Svedbom A, Ivergard M, Compston J. Osteoporosis in the European Union: medical management, epidemiology and economic burden. Arch Osteoporos. 2013;8:136.

3. Sowers MR, Zheng H, Greendale GA, Neer RM, Cauley JA, Ellis $\mathrm{J}$, et al. Changes in bone resorption across the menopause transition: effects of reproductive hormones, body size, and ethnicity. $\mathrm{J}$ Clin Endocrinol Metab. 2013;98(7):2854-63.

4. Torgerson DJ, Bell-Syer SE. Hormone replacement therapy and prevention of vertebral fractures: a meta-analysis of randomised trials. BMC Musculoskelet Disord. 2001;2:7.

5. Torgerson DJ, Bell Syer SE. Hormone replacement therapy and prevention of nonvertebral fractures: a meta-analysis of randomized trials. JAMA. 2001;285(22):2891-7.

6. Greenspan SL, Resnick NM, Parker RA. Combination therapy with hormone replacement and alendronate for prevention of bone loss in elderly women: a randomized controlled trial. JAMA. 2003;289(19):2525-33.

7. Effects of hormone therapy on bone mineral density: results from the postmenopausal estrogen/progestin interventions (PEPI) trial. The Writing Group for the PEPI. JAMA. 1996;276(17):1389-96.

8. Barrett-Connor E, Wehren LE, Siris ES, Miller P, Chen YT, Abbott TA 3rd, et al. Recency and duration of postmenopausal hormone therapy: effects on bone mineral density and fracture risk in the National Osteoporosis Risk Assessment (NORA) study. Menopause. 2003;10(5):412-9.

9. Rossouw JE, Anderson GL, Prentice RL, LaCroix AZ, Kooperberg C, Stefanick ML, et al. Risks and benefits of estrogen plus progestin in healthy postmenopausal women: principal results From the Women's Health Initiative randomized controlled trial. JAMA. 2002;288(3):321-33.

10. Anderson GL, Limacher M, Assaf AR, Bassford T, Beresford SA, Black $\mathrm{H}$, et al. Effects of conjugated equine estrogen in postmenopausal women with hysterectomy: the Women's Health Initiative randomized controlled trial. JAMA. 2004;291(14):1701-12.

11. Yates J, Barrett-Connor E, Barlas S, Chen YT, Miller PD, Siris ES. Rapid loss of hip fracture protection after estrogen cessation: evidence from the National Osteoporosis Risk Assessment. Obstet Gynecol. 2004;103(3):440-6.

12. Beral V. Breast cancer and hormone-replacement therapy in the Million Women Study. Lancet. 2003;362(9382):419-27.

13. Manson JE, Chlebowski RT, Stefanick ML, Aragaki AK, Rossouw JE, Prentice RL, et al. Menopausal hormone therapy and health outcomes during the intervention and extended poststopping phases of the Women's Health Initiative randomized trials. JAMA. 2013;310(13):1353-68.

14. Cauley JA. The Women's Health Initiative: hormone therapy and calcium/vitamin D supplementation trials. Curr Osteoporos Rep. 2013;11(3):171-8.

15. Banks E, Beral V, Reeves G, Balkwill A, Barnes I. Million Women Study C. Fracture incidence in relation to the pattern of use of hormone therapy in postmenopausal women. JAMA. 2004;291(18):2212-20.

16. Zhu L, Jiang X, Sun Y, Shu W. Effect of hormone therapy on the risk of bone fractures: a systematic review and meta-analysis of 
randomized controlled trials. Menopause. 2016;23(4):461-70 This meta-analysis documents that MHT is associated with a reduced risk of total, hip, and vertebral fractures, with a possible attenuation of this protection effect after it is stopped or when it is begun after 60 years.

17. Prior JC, Seifert-Klauss VR, Giustini D, Adachi JD, Kalyan S, Goshtasebi A. Estrogen-progestin therapy causes a greater increase in spinal bone mineral density than estrogen therapy - a systematic review and meta-analysis of controlled trials with direct randomization. J Musculoskelet Neuronal Interact. 2017;17(3): $146-54$

18. Prestwood KM, Kenny AM, Kleppinger A, Kulldorff M. Ultralow-dose micronized 17beta-estradiol and bone density and bone metabolism in older women: a randomized controlled trial. JAMA. 2003;290(8):1042-8.

19. Sharp CA, Evans SF, Risteli L, Risteli J, Worsfold M, Davie MW. Effects of low- and conventional-dose transcutaneous HRT over 2 years on bone metabolism in younger and older postmenopausal women. Eur J Clin Investig. 1996;26(9):763-71.

20. Ettinger B, Ensrud KE, Wallace R, Johnson KC, Cummings SR, Yankov V, et al. Effects of ultralow-dose transdermal estradiol on bone mineral density: a randomized clinical trial. Obstet Gynecol. 2004;104(3):443-51.

21. Warming L, Ravn P, Christiansen C. Levonorgestrel and 17betaestradiol given transdermally for the prevention of postmenopausal osteoporosis. Maturitas. 2005;50(2):78-85.

22. Abdi F, Mobedi H, Bayat F, Mosaffa N, Dolatian M, Ramezani Tehrani F. The effects of transdermal estrogen delivery on bone mineral density in postmenopausal women: a meta-analysis. Iran J Pharm Res. 2017;16(1):380-9.

23. Notelovitz M, John VA, Good WR. Effectiveness of Alora estradiol matrix transdermal delivery system in improving lumbar bone mineral density in healthy, postmenopausal women. Menopause. 2002;9(5):343-53.

24. Nielsen TF, Ravn P, Bagger YZ, Warming L, Christiansen C. Pulsed estrogen therapy in prevention of postmenopausal osteoporosis. A 2-year randomized, double blind, placebo-controlled study. Osteoporos Int. 2004;15(2):168-74.

25. Beck TJ, Stone KL, Oreskovic TL, Hochberg MC, Nevitt MC, Genant HK, et al. Effects of current and discontinued estrogen replacement therapy on hip structural geometry: the study of osteoporotic fractures. J Bone Miner Res. 2001;16(11):2103-10.

26. Greenspan SL, Emkey RD, Bone HG, Weiss SR, Bell NH, Downs $\mathrm{RW}$, et al. Significant differential effects of alendronate, estrogen, or combination therapy on the rate of bone loss after discontinuation of treatment of postmenopausal osteoporosis. A randomized, double-blind, placebo-controlled trial. Ann Intern Med. 2002;137(11):875-83.

27. Greendale GA, Espeland M, Slone S, Marcus R, Barrett CE. Bone mass response to discontinuation of long-term hormone replacement therapy: results from the Postmenopausal Estrogen/ Progestin Interventions (PEPI) safety follow-up study. Arch Intern Med. 2002;162(6):665-72.

28. Bagger YZ, Tanko LB, Alexandersen P, Hansen HB, Mollgaard A, Ravn P, et al. Two to three years of hormone replacement treatment in healthy women have long-term preventive effects on bone mass and osteoporotic fractures: the PERF study. Bone. 2004;34(4):728-35 According to this paper, limited MHT administered in the early postmenopausal years offers longlasting benefits for the prevention of postmenopausal bone loss and osteoporotic fracture.

29. Stepan JJ, Pospichal J, Presl J, Pacovsky V. Bone loss and biochemical indices of bone remodeling in surgically induced postmenopausal women. Bone. 1987;8(5):279-84.
30. Garnero P, Sornay Rendu E, Chapuy MC, Delmas PD. Increased bone turnover in late postmenopausal women is a major determinant of osteoporosis. J Bone Miner Res. 1996;11(3):337-49.

31. McLean RR. Proinflammatory cytokines and osteoporosis. Curr Osteoporos Rep. 2009;7(4):134-9.

32. Ponzetti M, Rucci N. Updates on osteoimmunology: what's new on the cross-talk between bone and immune system. Front Endocrinol. 2019;10:236 This paper provides a state-of-theart review of the mechanisms regulating the bone-immune system interplay.

33. Pacifici R, Brown C, Puscheck E, Friedrich E, Slatopolsky E, Maggio D, et al. Effect of surgical menopause and estrogen replacement on cytokine release from human blood mononuclear cells. Proc Natl Acad Sci U S A. 1991;88(12):5134-8.

34. D'Amelio P, Grimaldi A, Di Bella S, Brianza SZ, Cristofaro MA, Tamone C, et al. Estrogen deficiency increases osteoclastogenesis up-regulating T cells activity: a key mechanism in osteoporosis. Bone. 2008;43(1):92-100.

35. Adeel S, Singh K, Vydareny KH, Kumari M, Shah E, Weitzmann $\mathrm{MN}$, et al. Bone loss in surgically ovariectomized premenopausal women is associated with T lymphocyte activation and thymic hypertrophy. J Investig Med. 2013;61(8):1178-83.

36. Eghbali-Fatourechi G, Khosla S, Sanyal A, Boyle WJ, Lacey DL, Riggs BL. Role of RANK ligand in mediating increased bone resorption in early postmenopausal women. J Clin Invest. 2003;111(8):1221-30.

37. Molnar I, Bohaty I, Somogyine-Vari E. IL-17A-mediated sRANK ligand elevation involved in postmenopausal osteoporosis. Osteoporos Int. 2014;25(2):783-6.

38. Pineda B, Serna E, Laguna-Fernandez A, Noguera I, Panach L, Hermenegildo $\mathrm{C}$, et al. Gene expression profile induced by ovariectomy in bone marrow of mice: a functional approach to identify new candidate genes associated to osteoporosis risk in women. Bone. 2014;65:33-41.

39. Manolagas SC, Almeida M. Gone with the Wnts: beta-catenin, Tcell factor, forkhead box $\mathrm{O}$, and oxidative stress in age-dependent diseases of bone, lipid, and glucose metabolism. Mol Endocrinol. 2007;21(11):2605-14

40. Sapir-Koren R, Livshits G. Postmenopausal osteoporosis in rheumatoid arthritis: the estrogen deficiency-immune mechanisms link. Bone. 2017;103:102-15.

41. Li JY, Chassaing B, Tyagi AM, Vaccaro C, Luo T, Adams J, et al. Sex steroid deficiency-associated bone loss is microbiota dependent and prevented by probiotics. J Clin Invest. 2016;126(6): 2049-63.

42. Kverka M, Tlaskalova-Hogenova H. Intestinal microbiota: facts and fiction. Dig Dis. 2017;35(1-2):139-47.

43. Liu H, Luo T, Tan J, Li M, Guo J. 'Osteoimmunology' offers new perspectives for the treatment of pathological bone loss. Curr Pharm Des. 2017;23(41):6272-8.

44. Tlaskalova-Hogenova H, Stepankova R, Kozakova H, Hudcovic T, Vannucci L, Tuckova L, et al. The role of gut microbiota (commensal bacteria) and the mucosal barrier in the pathogenesis of inflammatory and autoimmune diseases and cancer: contribution of germ-free and gnotobiotic animal models of human diseases. Cell Mol Immunol. 2011;8(2):110-20.

45. Capaldo CT, Nusrat A. Cytokine regulation of tight junctions. Biochim Biophys Acta. 2009;1788(4):864-71.

46. Taneja V. Microbiome in 2016: $\mathrm{T}$ follicular helper cells and the gut microbiome in arthritis. Nat Rev Rheumatol. 2017;13(2):72-4.

47. Benedek G, Zhang J, Nguyen H, Kent G, Seifert HA, Davin S, et al. Estrogen protection against EAE modulates the microbiota and mucosal-associated regulatory cells. J Neuroimmunol. 2017;310:51-9.

48. Gomez A, Luckey D, Taneja V. The gut microbiome in autoimmunity: sex matters. Clin Immunol. 2015;159(2):154-62. 
49. Hughes DE, Dai A, Tiffee JC, Li HH, Mundy GR, Boyce BF. Estrogen promotes apoptosis of murine osteoclasts mediated by TGF-beta. Nat Med. 1996;2(10):1132-6.

50. Srivastava S, Toraldo G, Weitzmann MN, Cenci S, Ross FP, Pacifici R. Estrogen decreases osteoclast formation by downregulating receptor activator of NF-kappa B ligand (RANKL)induced JNK activation. J Biol Chem. 2001;276(12):8836-40.

51. Weitzmann MN, Pacifici R. Estrogen deficiency and bone loss: an inflammatory tale. J Clin Invest. 2006;116(5):1186-94.

52. Charatcharoenwitthaya N, Khosla S, Atkinson EJ, McCready LK, Riggs BL. Effect of blockade of TNF-alpha and interleukin-1 action on bone resorption in early postmenopausal women. J Bone Miner Res. 2007;22(5):724-9.

53. Manolagas SC, O'Brien CA, Almeida $\mathrm{M}$. The role of estrogen and androgen receptors in bone health and disease. Nat Rev Endocrinol. 2013;9:699-712.

54. Drake MT, Khosla S. Hormonal and systemic regulation of sclerostin. Bone. 2017;96:8-17.

55. Wang FS, Wu RW, Lain WS, Tsai TC, Chen YS, Sun YC, et al. Sclerostin vaccination mitigates estrogen deficiency induction of bone mass loss and microstructure deterioration. Bone. 2018;112: 24-34.

56. Farr JN, Roforth MM, Fujita K, Nicks KM, Cunningham JM, Atkinson EJ, et al. Effects of age and estrogen on skeletal gene expression in humans as assessed by RNA sequencing. PLoS One. 2015;10(9):e0138347.

57. Khastgir G, Studd J, Holland N, Alaghband-Zadeh J, Fox S, Chow $\mathrm{J}$. Anabolic effect of estrogen replacement on bone in postmenopausal women with osteoporosis: histomorphometric evidence in a longitudinal study. J Clin Endocrinol Metab. 2001;86(1):28995.

58. Eriksen EF, Langdahl B, Vesterby A, Rungby J, Kassem M. Hormone replacement therapy prevents osteoclastic hyperactivity: a histomorphometric study in early postmenopausal women. J Bone Miner Res. 1999;14(7):1217-21 This paper demonstrated reduction of osteoclastic bone resorption in women treated with MHT.

59. Prestwood KM, Gunness M, Muchmore DB, Lu Y, Wong M, Raisz LG. A comparison of the effects of raloxifene and estrogen on bone in postmenopausal women. J Clin Endocrinol Metab. 2000;85(6):2197-202.

60. Reid IR, Horne AM, Mihov B, Stewart A, Garratt E, Wong S, et al. Fracture prevention with zoledronate in older women with osteopenia. N Engl J Med. 2018;379(25):2407-16.

61. Harris ST, Watts NB, Genant HK, McKeever CD, Hangartner T, Keller M, et al. Effects of risedronate treatment on vertebral and nonvertebral fractures in women with postmenopausal osteoporosis: a randomized controlled trial. Vertebral Efficacy With Risedronate Therapy (VERT) Study Group. JAMA. 1999;282(14):1344-52.

62. Cummings SR, San Martin J, McClung MR, Siris ES, Eastell R, Reid IR, et al. Denosumab for prevention of fractures in postmenopausal women with osteoporosis. N Engl J Med. 2009;361(8): 756-65.

63. Borah B, Dufresne TE, Chmielewski PA, Johnson TD, Chines A, Manhart MD. Risedronate preserves bone architecture in postmenopausal women with osteoporosis as measured by threedimensional microcomputed tomography. Bone. 2004;34(4): 736-46.

64. Eriksen EF, Melsen F, Sod E, Barton I, Chines A. Effects of longterm risedronate on bone quality and bone turnover in women with postmenopausal osteoporosis. Bone. 2002;31(5):620-5.

65. Chavassieux PM, Arlot ME, Reda C, Wei L, Yates AJ, Meunier PJ. Histomorphometric assessment of the long-term effects of alendronate on bone quality and remodeling in patients with osteoporosis. J Clin Invest. 1997;100(6):1475-80.
66. Recker RR, Delmas PD, Halse J, Reid IR, Boonen S, GarciaHernandez PA, et al. Effects of intravenous zoledronic acid once yearly on bone remodeling and bone structure. J Bone Miner Res. 2008;23(1):6-16.

67. Brown JP, Reid IR, Wagman RB, Kendler D, Miller PD, Jensen $\mathrm{JE}$, et al. Effects of up to 5 years of denosumab treatment on bone histology and histomorphometry: the FREEDOM study extension. J Bone Miner Res. 2014;29(9):2051-6.

68. Mashiba T, Hirano T, Turner CH, Forwood MR, Johnston CC, Burr DB. Suppressed bone turnover by bisphosphonates increases microdamage accumulation and reduces some biomechanical properties in dog rib. J Bone Miner Res. 2000;15(4):613-20.

69. Bala Y, Farlay D, Chapurlat RD, Boivin G. Modifications of bone material properties in postmenopausal osteoporotic women longterm treated with alendronate. Eur J Endocrinol. 2011;165:64755.

70. Bala Y, Depalle B, Farlay D, Douillard T, Meille S, Follet H, et al. Bone micromechanical properties are compromised during longterm alendronate therapy independently of mineralization. J Bone Miner Res. 2012;27(4):825-34.

71. Pienkowski D, Wood CL, Malluche HH. Young's modulus and hardness of human trabecular bone with bisphosphonate treatment durations up to 20 years. Osteoporos Int. 2019;30(2):277-85.

72. Nyman JS, Makowski AJ. The contribution of the extracellular matrix to the fracture resistance of bone. Curr Osteoporos Rep. 2012;10:169-77.

73. Kong YY, Feige U, Sarosi I, Bolon B, Tafuri A, Morony S, et al. Activated $\mathrm{T}$ cells regulate bone loss and joint destruction in adjuvant arthritis through osteoprotegerin ligand. Nature. 1999;402(6759):304-9.

74. Greising SM, Baltgalvis KA, Lowe DA, Warren GL. Hormone therapy and skeletal muscle strength: a meta-analysis. J Gerontol A Biol Sci Med Sci. 2009;64(10):1071-81.

75. Collins BC, Laakkonen EK, Lowe DA. Aging of the musculoskeletal system: How the loss of estrogen impacts muscle strength. Bone. 2019;123:137-44 This review focuses on mechanisms that contribute to the loss of muscle force generation, when estrogen is low in females, and conversely the maintenance of strength by estrogen.

76. Uchiyama S, Ikegami S, Kamimura M, Mukaiyama K, Nakamura Y, Nonaka K, et al. The skeletal muscle cross sectional area in long-term bisphosphonate users is smaller than that of bone mineral density-matched controls with increased serum pentosidine concentrations. Bone. 2015;75:84-7.

77. Muscat Baron Y, Brincat MP, Galea R, Calleja N. Low intervertebral disc height in postmenopausal women with osteoporotic vertebral fractures compared to hormone-treated and untreated postmenopausal women and premenopausal women without fractures. Climacteric. 2007;10(4):314-9.

78. Lou C, Chen HL, Feng XZ, Xiang GH, Zhu SP, Tian NF, et al. Menopause is associated with lumbar disc degeneration: a review of 4230 intervertebral discs. Climacteric. 2014;17(6):700-4.

79. Oestergaard S, Sondergaard BC, Hoegh-Andersen P, Henriksen $\mathrm{K}$, Qvist P, Christiansen C, et al. Effects of ovariectomy and estrogen therapy on type II collagen degradation and structural integrity of articular cartilage in rats: implications of the time of initiation. Arthritis Rheum. 2006;54(8):2441-51.

80. Santen RJ, Allred DC, Ardoin SP, Archer DF, Boyd N, Braunstein GD, et al. Postmenopausal hormone therapy: an Endocrine Society scientific statement. J Clin Endocrinol Metab. 2010;95(7 Suppl 1):s1-s66.

81. Menopause: diagnosis and management, NICE guidelines [NG23]. https://www.nice.org.uk/guidance/. 2015.

82. Baber RJ, Panay N, Fenton A, Group IMSW. 2016 IMS Recommendations on women's midlife health and menopause hormone therapy. Climacteric. 2016;19(2):109-50. 
83. Stuenkel CA, Davis SR, Gompel A, Lumsden MA, Murad MH, Pinkerton JV, et al. Treatment of symptoms of the menopause: an Endocrine Society Clinical Practice Guideline. J Clin Endocrinol Metab. 2015;100(11):3975-4011.

84.• The 2017 hormone therapy position statement of The North American Menopause Society. Menopause. 2018;25(11):136287 According to his statement, the MHT benefit-risk ratio is favorable for women aged younger than 60 years or who are within 10 years of menopause onset, have no contraindications, and are at elevated risk for bone loss or fracture.

85. Hsia J, Langer RD, Manson JE, Kuller L, Johnson KC, Hendrix SL, et al. Conjugated equine estrogens and coronary heart disease: the Women's Health Initiative. Arch Intern Med. 2006;166(3): 357-65.

86. Chen WY, Manson JE, Hankinson SE, Rosner B, Holmes MD, Willett WC, et al. Unopposed estrogen therapy and the risk of invasive breast cancer. Arch Intern Med. 2006;166(9):1027-32.

87.• Manson JE, Aragaki AK, Rossouw JE, Anderson GL, Prentice RL, LaCroix AZ, et al. Menopausal hormone therapy and longterm all-cause and cause-specific mortality: the Women's Health Initiative randomized trials. JAMA. 2017;318(10):927-38 This paper summarizes the outcomes of the WHI trial during the intervention phase, postintervention and overall.

88. Chlebowski RT, Rohan TE, Manson JE, Aragaki AK, Kaunitz A, Stefanick ML, et al. Breast cancer after use of estrogen plus progestin and estrogen alone: Analyses of data from 2 Women's Health Initiative randomized clinical trials. JAMA Oncol. 2015;1(3):296-305.

89. Santen RJ, Yue W. Cause or prevention of breast cancer with estrogens: analysis from tumor biologic data, growth kinetic model and Women's Health Initiative study. Climacteric. 2019;22(1): 3-12 This paper provides emerging concepts of tumor biology and interpretation of breast cancer risk in the estrogen-alone arm of the WHI.

90.• Collaborative Group on Hormonal Factors in Breast Cancer. Type and timing of menopausal hormone therapy and breast cancer risk: individual participant metaanalysis of the worldwide epidemiological evidence. Lancet. 2019; 394(10204):1159-1168. This meta-analysis provides the epidemiological evidence that 5 years of MHT use, starting at age 50 years, would cause an appreciable increase in the probability of developing breast cancer at ages 50-69 years.

91. Mirkin S. Evidence on the use of progesterone in menopausal hormone therapy. Climacteric. 2018;21(4):346-54.

92. Kotsopoulos J, Gronwald J, Karlan BY, Huzarski T, Tung N, Moller P, et al. Hormone replacement therapy after oophorectomy and breast cancer risk among BRCA1 mutation carriers. JAMA Oncol. 2018;4(8):1059-65.

93. Yang Z, Hu Y, Zhang J, Xu L, Zeng R, Kang D. Estradiol therapy and breast cancer risk in perimenopausal and postmenopausal women: a systematic review and meta-analysis. Gynecol Endocrinol. 2017;33(2):87-92.

94. Shufelt C, Bairey Merz CN, Pettinger MB, Choi L, Chlebowski R, Crandall CJ, et al. Estrogen-alone therapy and invasive breast cancer incidence by dose, formulation, and route of delivery: findings from the WHI observational study. Menopause. 2018;25(9): 985-91 This paper suggests that the lower breast cancer risk found in the WHI estrogen-alone trial may extend to lower doses of CEE.
95. Boardman HM, Hartley L, Eisinga A, Main C, Roque i Figuls M, Bonfill Cosp X, et al. Hormone therapy for preventing cardiovascular disease in post-menopausal women. Cochrane Database Syst Rev. 2015;10(3):CD002229.

96. Scarabin PY. Progestogens and venous thromboembolism in menopausal women: an updated oral versus transdermal estrogen meta-analysis. Climacteric. 2018;21(4):341-5 This paper documents the safety advantage of transdermal estrogen combined with progesterone and supports the current evidence-based recommendations on $\mathrm{HT}$, especially in women at high VTE risk.

97. Oger E, Alhenc-Gelas M, Lacut K, Blouch MT, Roudaut N, Kerlan V, et al. Differential effects of oral and transdermal estrogen/progesterone regimens on sensitivity to activated protein $\mathrm{C}$ among postmenopausal women: a randomized trial. Arterioscler Thromb Vasc Biol. 2003;23(9):1671-6.

98. Scarabin PY, Hemker HC, Clement C, Soisson V, Alhenc-Gelas $\mathrm{M}$. Increased thrombin generation among postmenopausal women using hormone therapy: importance of the route of estrogen administration and progestogens. Menopause. 2011;18(8):873-9.

99. Rahkola-Soisalo P, Savolainen-Peltonen H, Gissler M, Hoti F, Vattulainen P, Ylikorkala O, et al. Postmenopausal hormone therapy is accompanied by elevated risk for uterine prolapse. Menopause. 2019;26(2):140-4.

100. Richman S, Edusa V, Fadiel A, Naftolin F. Low-dose estrogen therapy for prevention of osteoporosis: working our way back to monotherapy. Menopause. 2006;13(1):148-55.

101. Rahkola-Soisalo P, Savolainen-Peltonen H, Gissler M, Hoti F, Vattulainen $\mathrm{P}$, Ylikorkala $\mathrm{O}$, et al. Increased risk for stress urinary incontinence in women with postmenopausal hormone therapy. Int Urogynecol J. 2019;30(2):251-6.

102. Wehrli FW, Ladinsky GA, Jones C, Benito M, Magland J, Vasilic $\mathrm{B}$, et al. In vivo magnetic resonance detects rapid remodeling changes in the topology of the trabecular bone network after menopause and the protective effect of estradiol. J Bone Miner Res. 2008;23(5):730-40.

103. Siris ES, Harris ST, Eastell R, Zanchetta JR, Goemaere S, DiezPerez A, et al. Skeletal effects of raloxifene after 8 years: results from the continuing outcomes relevant to Evista (CORE) study. J Bone Miner Res. 2005;20(9):1514-1524.

104. Cauley JA, Norton L, Lippman ME, Eckert S, Krueger KA, Purdie $\mathrm{DW}$, et al. Continued breast cancer risk reduction in postmenopausal women treated with raloxifene: 4-year results from the MORE trial. Multiple outcomes of raloxifene evaluation. Breast Cancer Res Treat. 2001;65(2):125-134.

105. Silverman SL, Christiansen C, Genant HK, Vukicevic S, Zanchetta JR, de Villiers TJ, et al. Efficacy of bazedoxifene in reducing new vertebral fracture risk in postmenopausal women with osteoporosis: results from a 3-year, randomized, placebo-, and activecontrolled clinical trial. J Bone Miner Res. 2008;23(12):1923-1934.

106. Palacios S, Silverman SL, de Villiers TJ, Levine AB, Goemaere S, Brown JP, et al. A 7-year randomized, placebo-controlled trial assessing the long-term efficacy and safety of bazedoxifene in postmenopausal women with osteoporosis: effects on bone density and fracture. Menopause. 2015;22(8):806-813.

Publisher's Note Springer Nature remains neutral with regard to jurisdictional claims in published maps and institutional affiliations. 